\title{
Do as I say, not as I do...
}

\section{Driving ethical leadership towards employee outcomes in an emerging market}

\author{
[Dawie (D.A.J.) Bornman]
}

Abstract - In an emerging market such as South African, corporate governing bodies such as the King Code legitimise and promote ethical codes and their importance in organisations (South African Institute of Chartered Accountants, 2017:11-12). As employees have frequent customer interactions, and the quality of these interaction directly affect the customer's perception of the organisation; an aspect such as ethical leadership should not be ignored as it greatly affects employees which in turn impacts organisational performance. Bornman and Puth (2017:6) identified four main aspects of what leadership is: (1) it is about who you are, (2) how you act, (3) what you do, and (4) how a leader works with others. Ethical leadership fuses these principles together and includes the fair treatment of employees, integrity and setting ethical guidelines (Yukl, Mahsud, Hassan \& Prussia, 2013:38; Yang \& Wei, 2018), and according to Shin, Sung, Choi and Kim (2015:45), employees learn ethical behavior from their leaders. The purpose of this qualitative study was to examine employees' perceptions of the relationship between ethical leadership and selected employee outcomes (i.e. (1) organisational commitment, (2) job satisfaction, (3) employee satisfaction and (4) extra effort). For leaders, the study highlights the importance of leading ethically due to the effect on the selected employee outcomes. The employee outcomes in turn then have an effect an organisation's performance through the quality of the organisation's products, services and customer service. The study collected data through twelve semistructured interviews which were one-on-one, and were conducted at twelve different organisations in Gauteng, South Africa. By asking open-ended questions, participants were able to voice their experiences in their own words, in the true sense. Open-ended questions prevented the participants from falling victim to potential researcher bias, but instead allow them to freely answer the questions posed (Creswell, 2012:218). The data collected during the study was analysed using a thematic analysis which is a process of identifying, organising and reporting on themes from data collected (Braun \& Clarke, 2012:57). In terms of determining whether or not employees imitate their leaders' behaviour, the study found that most employees base their behaviour on their own morals regardless of how ethical they perceive their leaders to be. Therefore, most employees do not imitate their leaders' behaviour which contradicts literature of Keskes, Sallan, Simo and Fernandez (2018); Kim and Brymer (2011:1021); Shin et al. (2015:45); Yidong and Xinxin (2013:442) as the vast majority of employees did not want to compromise their own morals. In the study, it is also ascertained in which cases employees may imitate their leader's behaviour, and how this will have certain managerial implication, as well as, limitations and recommendations for future research and practice.

Keywords - Ethical leadership, employee perceptions, organisational commitment, job satisfaction, employee satisfaction, and extra effort

\section{Introduction}

Profit and return on investment are essential for an organisation to have longevity and continuity, and it has been argued that employees are among the most critical drivers of this (Askew, Beisler \& Keel, 2015:108; Shin, Sung, Choi \& Kim, 2015:46). Employees can be described as the foot soldiers of an army and are at the forefront of the organisation. There is no doubt that motivated employees will result in increased profit and return on investment (Kim, Leong \& Lee, 2005:189). However, whilst employees play a crucial role, the leaders provide direction and set the tone of acceptable behaviour of the organisation, and can be described as the generals of the army. Knowing that employees play a crucial role in an organisation, how does ethical leadership impact employee outcomes and therefore the long-term goals of an organisation, i.e. profit and return on investment?

Leadership involves motivating employees to strive toward achieving collective organisational goals (Lawal, Ajonbadi \& Otokiti, 2014:122). In essence, ethical leadership refers to the demonstration of honest and fair conduct of leaders' actions and upholding the ethical standards and codes. Ethical leadership is built on the fair treatment of employees, integrity and setting ethical guidelines (Yukl, Mahsud, Hassan \& Prussia, 2013:38) and employees learn ethical behaviour from their leaders (Shin et al., 2015:45). Leaders should simultaneously praise employees' proper ethical conduct and discipline wrongdoers since unethical leadership has detrimental consequences for selected employee outcomes. These negative consequences effect: (1) organisational commitment, (2) job satisfaction, (3) employee satisfaction and (4) extra effort which in turn has a negative effect on organisational performance, such as slow growth (Askew et al., 2015:108). In a South African setting, corporate governing bodies such as the King Code legitimise and promote ethical codes and their importance in organisations (South African Institute of Chartered Accountants, 2017:1112).

Although previous research confirms the importance of ethical leadership on employee outcomes, this research has primarily focused on organisations' middle and top managers as opposed to the employees 'on the frontline' of an organisation. While this research is beneficial, there is a problem because it does not cover employees who have a significant impact on organisations due to their high frequency of customer contact and because the quantity and quality of an organisation's products and services rely on its interactions and employees (Shin et al., 2015:44-46).

Within an emerging market, such as the South African context, there have not been many prior studies that have investigated ethical leadership and employee outcomes. Additionally, the studies that have been concluded have only focused on a single industry: hospitality (Kim \& Brymer, 2011:1023; Quintana, Park \& Cabrera, 2014:475; Shin et al., 2015:48; Tahernejad, Ariffin Raja, Ghorban Seyed \& Babaei, 2015:92). Shin et al. (2015:54-55) and Kim and Brymer (2011:1025) recommended that further research is required across other industries. Unethical leadership has 
detrimental consequences for organisations such as slow performance and growth through lowered employee performance and commitment (Askew et al., 2015:108). This highlights the significance of why further research is required to investigate how ethical leadership affects employee outcomes.

The purpose of this basic qualitative study is to examine employees' perceptions of the relationship between ethical leadership and selected employee outcomes. The selected employee outcomes that will be discussed are: (1) employee commitment, (2) job satisfaction, (3) employee satisfaction and (4) extra effort. As this study is a basic qualitative study, it indicates that it will focus on exploring the participants' experience or perceptions about the topic (Percy, Kostere \& Kostere, 2015:78; University of Pretoria, 2017a:12-14).

The following research questions will guide this study:

- Do organisational ethical guidelines reduce unethical behaviour?

- Do employees imitate their leaders' behaviour if the leader is perceived as ethical?

- In terms of ethical leadership, which ethical- or leadership drivers create employee commitment to the organisation?

- How does leaders' ethical leadership affect employees' job satisfaction?

- In terms of employee satisfaction, do job-attributes or ethical leadership play a more prominent role? Job-attributes refer to: (1) organisational culture, (2) relationship with colleagues, (3) consistency in pay and (4) agreements between leaders and employees are upheld and complied with.

- How will extra effort (i.e. exceeding managers' expectations) be influenced by whether or not leadership is ethical?

- To what extent does ethical leadership impact selected employee outcomes (i.e. (1) employee commitment, (2) job satisfaction, (3) employee satisfaction and (4) extra effort)?

The contribution of this research includes meaningful additions to the literature of ethical leadership and employee outcomes. This study will expand on the knowledge of ethical leadership by critically evaluating the leaders' ethical behaviour and the impact it has on selected employee outcomes. The employee outcomes affect an organisation's performance through the quality of its products, services and customer service.

\section{Literature}

\section{A. Leadership}

Lawal et al. (2014:122) defined leadership as "the art of influencing people so that they will strive willingly and enthusiastically toward the achievement of group goals." This is further supported by (Grobler \& du Plessis, 2016:3). Therefore, leadership is an important issue for organisations who compete in the national and international markets (Bornman \& Puth, 2017:2).
The leadership activity needs followers in order to exist, so a leader can influence the follower's feelings, behaviour and beliefs in a predetermined direction (Lawal et al., 2014:122). Bornman and Puth (2017:6) identified four main aspects of what leadership is: (1) it is about who you are, (2) how you act, (3) what you do, and (4) how a leader works with others.

According to Wahab, Rahmat, Yusof and Mohamed (2015:595), an organisation must understand the importance of leadership because it is the driving force of a firm's performance. A key aspect of leadership is how the leader inspires employees to achieve the organisation's goal or to accept change (Bornman \& Puth, 2017:2).

South African organisations have exceptional leaders with world-class leadership quality; South Africa, however, still performs poorly according to the World Competitiveness Surveys. Therefore, South Africa needs to improve the identification and development of its leaders and create an organisational culture which will motivate and improve quality leadership (Mutsonziwa \& Serumaga-Zake, 2015:166).

\section{B. Ethical Leadership}

Ethical leadership refers to the display of honest and fair demeanour of leaders' personal actions and their interpersonal relationships, as well as the reinforcement of such demeanours to employees through using two-way communication, dispensing ethical standards and praising proper ethical conduct. Ethical leadership further includes disciplining both wrongdoers and those responsible for unethical decision-making. This shows that ethical leaders must act as moral people and managers. The characteristics of moral leaders are honesty, altruism, trustworthiness and integrity. It is clear that ethical leaders behave in ways that benefit others while refraining from causing harm to others. Organisations should consider their employees seriously; their behaviours and perceptions are as vital as (if not more vital than) organisational outcomes. Employees have a direct influence on the quantity and quality of products and services that an organisation offers. Furthermore, employees often interact with an organisation's customers (Shin et al., 2015:46) and is seen as the first contact point between the organisation and its customers.

Management can demonstrate ethical leadership by not compromising the organisation's ethical standards in order to achieve positive short-term, financial organisational performance (Piccolo, Greenbaum, Hartog \& Folger, 2010:262). Good organisational performance, for the purposes of this study, refers to the organisation's achievement of its strategic objectives (South African Institute of Chartered Accountants, 2016:11-12).

\section{Outcomes of Ethical Leadership}

Ethical leadership is an important topic in the fields of organisational behaviour and management. The fundamental results of ethical leadership are: (1) employees displaying greater commitment to the organisation, (2) higher levels of job and employee satisfaction and (3) exerting extra effort. 
(Kim \& Brymer, 2011:1021; Tahernejad et al., 2015:90). Mostly, organisations do not directly recognise employee outcomes; for example, employees do not get more compensation if they are committed, satisfied or put extra effort into their jobs (Shin et al., 2015:45).

\section{Methodology}

\section{A. Research Design}

The study investigated the impact of ethical leadership on selected drivers of employee outcomes (i.e., employee commitment, job satisfaction, employee satisfaction and extra effort). A basic qualitative research design was employed which investigated employees' own subjective beliefs, opinions, attitudes, perspectives or experiences regarding their manager's ethical leadership (Percy et al., 2015:78; University of Pretoria, 2017a:12-14). The study aimed to better understand and delve deeper into ethical leadership, through employee perspectives, and the effects it had on the selected employee outcomes.

\section{B. Sampling}

The unit of analysis for the study was individuals, more specifically the employees' perspectives of ethical leadership was investigated. The study defined an employee as an individual who works for a particular organisation and (although all managers are still employees) is not in a managerial position (Rupp, Ganapathi, Aguilera \& Williams, 2006:538). Twelve employees each from different organisations were interviewed. The researchers stopped at twelve interviews since data saturation would occur after twelve interviews (Guest, Bunce \& Johnson, 2006:74).

Individual participants were subjected to inclusion criteria of: (1) participants had, at a minimum, a matriculation certificate (South African Qualifications Authority, 2003); (2) individuals held no managerial position; (3) participants were older than twenty-one years of age. Individuals were sampled using the maximum variation sampling strategy where the individual's job title, industry, gender and experience purposefully differed throughout the sample, this created a diverse array of perspectives from the sample (Creswell, 2012:207).

The study created geographic, size and policy eligibility criteria when selecting organisations. The following inclusion criterion was used in the study: (1) located in Gauteng, (2) a medium to large-sized organisation and (3) ethical guidelines in place. Industry sectors for the study were organisations within the transport, manufacturing and retail industries. Conducting a study across three industries enabled diverse results and was consistent with recommendations of previous studies (Kim \& Brymer, 2011:1025; Shin et al., 2015:54-55). Researchers incurred a homogeneous cut-off point at industries since different sectors were selected for the study (Langbein \& Lichtman, 1978:21).

\section{Data Collection}

The study collected data through twelve semi-structured interviews which were one-on-one. By asking open-ended questions, participants were able to voice their experiences in their own words, in the true sense. Open-ended questions prevented the participants from falling victim to potential researcher bias, but instead allow them to answer freely (Creswell, 2012:218). This resulted in detailed knowledge of the participants' perspectives regarding the impact of ethical leadership on the employee's selected outcomes. Of the twelve semi-structured interviews, nine were face-to-face and three were telephonic as these participants were not able to meet with the researchers.

The discussion guide was created from an in-depth analyse of literature and was pre-tested using a two-phase process. During the first phase, the discussion guide was analysed by a qualitative research expert and by an experienced academic in the field of business management. During the second phase, the researchers interviewed a participant to determine issues such as clarity and then adapted interview questions accordingly (University of Pretoria, 2017b:1-2). The researchers were recommended to make minor changes to the discussion guide such as; adding the definitions of "job satisfaction" and "employee satisfaction" as the participant did not understand these two terms.

\section{Data Analysis}

The data collected during the study was analysed using a thematic analysis (Braun \& Clarke, 2012:57; Creswell, 2012:236-253; Nieuwenhuis, 2007:99-117). Data was organised by: sorting the data by type, labeling data items and making duplicate copies (University of Pretoria, 2016:34). Additionally, the interviews were recorded and transcribed. The audio-recordings were listened to several times and each transcript was read through multiple times to get familiarise with the data collected (Nieuwenhuis, 2007:104). Notes were made on the transcripts where applicable (Braun \& Clarke, 2012:61) and thereafter, a list of codes was compiled. Codes were revised which highlighted various patterns which then translated into themes (Braun \& Clarke, 2012:63-65).

\section{E. Trustworthiness and Ethical Considerations}

Trustworthiness was ensured using credibility, dependability, confirmability and transferability. Credibility was achieved through site triangulation whereby the researchers gained multiple perspectives on the topic by collecting data from multiple sites; this ensured that themes were not unique to a specific firm (Polit \& Beck, 2012:590). Frequent debriefing sessions with the researchers' study leader took place to critically analyse the approach. For dependability, an audit trial was conducted which explained detailed processes within the study (Shenton, 2004:71-72). For transferability, the study provided a "thick" description for the consumers to decide applicability (Polit \& Beck, 2012:585). Finally, to ensure confirmability, triangulation 
Proc. of The Eighth Intl. Conf. On Advances In Economics, Social Science and Human Behaviour Study - ESSHBS 2018 Copyright (C) Institute of Research Engineers and Doctors, USA. All rights reserved.

ISBN: 978-1-63248-156-6 doi: 10.15224/978-1-63248-156-6-20

was utilised to ascertain a link between the reviewed literature and collected data.

Furthermore, voluntary participation with the option to withdraw from the study at any time was explained in each consent form. To ensure anonymity and confidentiality the researchers used pseudonyms to remove each participant's name and each organisation's names from the transcripts and in the final article.

\section{Conclusion}

\section{A. Summary of Findings}

The purpose of this study was to examine employees' perceptions of the relationship between ethical leadership and selected employee outcomes (i.e. (1) employee commitment, (2) job satisfaction, (3) employee satisfaction and (4) extra effort). To understand the link between ethical guidelines and behaviour, research question 1 was posed to determine if organisational ethical guidelines reduce unethical behaviour. It was found that ethical guidelines promote ethical behaviour within an organisation, thereby exhibiting consistency with the literature (Askew et al., 2015:107). Herewith, the ethical guidelines should be clear and concise in order to promote an ethical atmosphere within the organisation. Therefore, this is in line with the findings of Askew et al. (2015:107); Kim and Brymer (2011:1021); Shin et al. (2015:44).

In terms of determining whether or not employees imitate their leaders' behaviour, the study found that most employees base their behaviour on their own morals regardless of how ethical they perceive their leaders to be. Therefore, most employees do not imitate their leaders' behaviour which contradicts literature of Kim and Brymer (2011:1021); Shin et al. (2015:45); Yidong and Xinxin (2013:442) as the vast majority of employees did not want to compromise their own morals.

It was found that ethical leadership is the driving force behind determining the extent to which employees reported feeling committed to their organisations. Here within, the attributes are: honesty, fairness, inter-personal relationships, two-way communication, altruism, trustworthiness and integrity which is consistent with the findings of Kim and Brymer (2011:1020-1021) and Yidong and Xinxin (2013:442). Moreover, organisation- and customerorientation of leaders further acts as drivers of employee commitment. Therefore, this conclusion corroborates with the above literature.

The research question relating to how ethical (or unethical) leadership impacts employees' job satisfaction, found that job satisfaction increases when leaders are ethical; this is consistent with the findings of Kim and Brymer (2011:1025). Additionally, when leaders discipline unethical behaviour, employees' job satisfaction further increases as employees feel that their morals are not overlooked as they may be held accountable for unethical. This finding supports those of Kim and Brymer (2011:1022) and Tahernejad et al. (2015:90).
Another employee outcome that is discussed is employee satisfaction which stems from both ethical leadership and job-related factors such as: (1) organisational culture, (2) pay, (3) teamwork, (4) career development, (5) working conditions and (6) responsibilities. The findings indicate that employees' satisfaction is derived from both ethical leadership and job-related factors. However, job-related factors are the main driver of employee satisfaction. Thereby, this finding confirms the literature of Mutsonziwa and Serumaga-Zake (2015:180).

Furthermore, ethical leadership's impact on extra effort has been analysed. It has been found that ethical leadership has the potential to enhance employees' extra effort. Employees are willing to exert more effort when their leader displays ethical attributes. The study's findings agree with literature (Piccolo et al., 2010:262; Quintana et al., 2014:472; Walumbwa et al., 2011:205). Furthermore, it was found that employee satisfaction is a pre-requisite for employees to exert extra effort which is consistent with Kim and Brymer (2011:1025).

Finally, the last research question sought to determine the extent of the impact of ethical leadership on the selected employee outcomes (i.e. (1) employee commitment, (2) job satisfaction, (3) employee satisfaction and (4) extra effort). The findings conclude that the selected employee outcomes are impacted greatly by ethical leadership which is consistent with literature (Kim \& Brymer, 2011:1022; Mutsonziwa \& Serumaga-Zake, 2015:180; Quintana et al., 2014:472; Tahernejad et al., 2015:91; Walumbwa et al., 2011:205).

\section{B. Managerial Implications, Limitations and Recommendations for Future Research}

In an emerging country such as South Africa, leaders should consider their employees seriously since their behaviours and perceptions are vital to organisational outcomes. The study emphasises that ethical leadership, as perceived by employees, can greatly affect selected employee outcomes when referring to (1) employee commitment, (2) job satisfaction, (3) employee satisfaction and (4) extra effort. Employees who are not committed, not satisfied and do not exert extra effort may perform poorly in their work. This in turn negatively impacts organisational performance. Like the soldiers representing an army, employees are imperative to the organisation's success.

Secondly, the study found that ethical guidelines promote ethical behaviour. However, leaders should ensure that the guidelines are clear and concise while minimising legal terminology to ensure that all employees understand and can adhere to the organisations' morals and values. This should ensure that an ethical atmosphere is created.

Although the study contributes to ethical leadership research, the findings are based on the perspectives of twelve employees from twelve different organisations. A potential problem might arise if the specific employee is 
Proc. of The Eighth Intl. Conf. On Advances In Economics, Social Science and Human Behaviour Study - ESSHBS 2018 Copyright (C) Institute of Research Engineers and Doctors, USA. All rights reserved.

ISBN: 978-1-63248-156-6 doi: 10.15224/978-1-63248-156-6-20

disgruntled with his / her leader, thereby conveying a biased reflection of the impact of ethical leadership on the selected employee outcomes. Future researchers should interview multiple employees from each organisation in order to represent an unbiased representation of the information collected.

Due to the sensitive nature of employees speaking about their leaders, a few employees were hesitant to share their true perspectives. Some participants came across as being fearful that their details may be leaked to their organisation, even though confidentiality and anonymity was stressed throughout the interviews. Semi-structured, face-to-face recorded interviews intimidated the participants in terms of conveying honest perspectives. Future researchers should use a quantitative data collection method to reduce the physical presence of the researchers and voice recorders. Additionally, a quantitative research design will assist in reducing the first mentioned limitation in that more participants can participate.

The study had a time constraint which resulted in limited time to conduct an in-depth and thorough investigation into a topic such as an ethnographic or case study research would do (Caelli, Ray \& Mill, 2003:2). The study did not focus on culture as ethnography does, furthermore, it did not build a theory as does grounded theory (University of Pretoria, 2017a:2). Therefore, a basic research design was the most appropriate approach for the study. Future researchers should approach employees directly to reduce wastage of time.

\section{Acknowledgment}

The author would like to acknowledge the reviewers of the draft manuscript, as well as $\mathrm{Mr} \mathrm{M}$. Dorrington and $\mathrm{Me}$ K. Hammann for their helpful assistance during the development, data collection and analyses of a draft version of this article.

\section{References}

[1] A.K. Shenton, "Strategies for ensuring trustworthiness in qualtative research projects," Education for Information, vol 22, 63-75, 2004.

[2] A.A. Lawal, H.A. Ajonbadi, and B.O Otokiti, "Leadership and organisational performance in the Nigeria small and medium enterprises (SMEs)," American Journal of Business, Economics and Management, vol 3(5), pp. 121-127, 2014.

[3] A. Tahernejad, R. Ariffin Raja, Z.S. Ghorban Seyed, and H. Babaei, “ Ethical leadership and employee-organisational outcomes in the hotel industry," South African Journal of Business Management, vol 46(2), pp. 89-98, 2015.

[4] D.A.J. Bornman, and G. Puth, "Investigating employee perceptions of leadership communication: a South African study," Journal of Contemporary Management, vol 14, pp. 1-23, 2017.

[5] D.E. Rupp, J. Ganapathi, R.V. Aguilera, and C.A. Williams, "Employee reactions to corporate social responsibility: an organizational justice framework," Journal of Organizational Behaviour, vol 27, pp. 537-543, 2006.

[6] D.F. Polit, and C.T. Beck, "Nursing research: generating and assessing evidence for nursing practice," 9th ed. Philadelphia, PA: Wolters Kluwer Health/Lippincott Williams \& Wilkins, 2012.

[7] G. Guest, A. Bunce, and L. Johnson, "How many interviews are enough? An experiment with data saturation and variability," Field Methods, vol 18(1), pp. 59-82, 2006.

[8] G. Yukl, R. Mahsud, S. Hassan, and G.E. Prussia, "An improved measure of ethical leadership," Journal of Leadership \& Organizational Studies, vol 20(1), pp. 38-48, 2013.

[9] I. Keskes, J.M. Sallan, P. Simo, and V. Fernandez, "Transformational leadership and organizational commitment: Mediating role of leadermember exchange," Journal of Management Development, vol 37(3), pp. 271-284, 2018.

[10] J.W. Creswell, "Education research: planning, conducting and evaluating quantitative and qualitative research," 4th ed. Boston, MA: Pearson, 2012.

[11] K. Mutsonziwa, and P. Serumaga-Zake, "Exploring employee satisfaction and leadership attributes within the research industries in Gauteng Province," Journal of Contemporary Management, vol 12, pp. 164-183, 2015.

[12] L.I. Langbein, and A.J. Lichtman, "Solutions to problems of aggregation bias," Ecological inference. Thousand Oaks, CA: SAGE. [Online] Available from: http://methods.sagepub.com/book/ecological-inference, 1978.

[13] O.A. Askew, J.M. Beisler, and J. Keel, "Current trends of unethical behavior within organizations," International Journal of Management \& Information Systems, vol 19(3), pp. 107-114, 2015.

[14] Q. Yang, and H. Wei, "The impact of ethical leadership on organizational citizenship behavior: The moderating role of workplace ostracism," Leadership \& Organization Development Journal, vol 39(1), pp. 100-113, 2018.

[15] R.F. Piccolo, R. Greenbaum, D.N.d. Hartog, and R. Folger, “ The relationship between ethical leadership and core job characteristics," Journal of Organizational Behavior, vol 31(2-3), pp. 259-278, 2010.

[16] South African Institute of Chartered Accountants. SAICA student handbook 2015/2016. Durban, SA: LexisNexis. 2017.

[17] S.W. Grobler, and Y. du Plessis, "Requisite leader behavioural competencies for sustainable organisational performance," Acta Commercii, vol 16(1), pp. 1-8, 2016.

[18] T.A. Quintana, S. Park, and Y.A. Cabrera, "Assessing the effects of leadership styles on employees' outcomes in international luxury hotels," Journal of Business Ethics, vol 129(2), pp. 469-489. 2014.

[19] T. Yidong, and L. Xinxin, "How ethical leadership influence employees' innovative work behavior: a perspective of intrinsic motivation," Journal of Business Ethics, vol 116(2), pp. 441-455, 2013.

[20] Y. Shin, S.Y. Sung, J.N. Choi, and M.S. Kim, "Top management ethical leadership and firm performance: mediating role of ethical and procedural justice climate," Journal of Business Ethics, vol 129, 4357, 2015.

[21] V. Braun, and V. Clarke, "Thematic analysis. In: Cooper, H. (ed.). APA handbook of research methods in psychology: volume 2 research designs," Washington, DC: American Psychological Association, 2012.

[22] W.H. Percy, K. Kostere, and S. Kostere, "Generic qualitative research in psychology," The Qualitative Report, vol 20(2), pp. 76-85.

[23] W.G. Kim, and R.A. Brymer, "The effects of ethical leadership on manager job satisfaction, commitment, behavioral outcomes, and firm performance," International Journal of Hospitality Management, vol 30(4), pp. 1020-1026, 2011.

About Author:

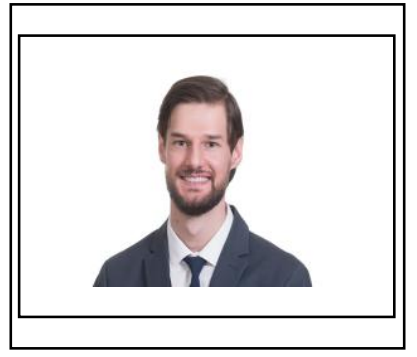

Dr Dawie Bornman is a senior lecturer and researcher in the department of Business Management at the University of Pretoria, South Africa. He has presented his research at numerous national and international conferences, doctoral seminars and personal development workshops focusing on Leadership Communication, Business Management and Entrepreneurial Innovation. 